\title{
A College Freshman Mindfulness Seminar to Enhance Psychological Well-being and Cognitive Function
}

Rongxiang Tang ${ }^{1 *}$, Patricia C. Broderick ${ }^{2}$, Timothy J. Bono ${ }^{1}$, Kamila Dvořáková ${ }^{2,3}$, Todd S. Braver $^{1 *}$

${ }^{1}$ Department of Psychological \& Brain Sciences, Washington University in St. Louis, St. Louis, Missouri, USA

${ }^{2}$ Edna Bennett Pierce Prevention Research Center, Pennsylvania State University, University Park, Pennsylvania, USA

${ }^{3}$ National Institute for Mental Health, Prague, The Czech Republic

\section{*Corresponding Author:}

Rongxiang Tang, M.A.

rongxiang@wustl.edu

Department of Psychological and Brain Sciences,

Washington University in St. Louis, St. Louis, Missouri, USA

\section{Conflict of Interest:}

The authors declare that they have no conflict of interest.

\section{Acknowledgements:}

We thank Kevin Oksanen for his assistance in data collection. 


\begin{abstract}
Mindfulness training has shown promise in improving psychological health and cognitive function. Mindfulness skills may be particularly beneficial in helping first-year students' transition to college, as this can be a time period of considerable lifestyle changes and increased stress. Previous research has demonstrated positive effects of mindfulness training in college populations, but primarily by providing standardized mindfulness programs that are distinct from the college curriculum. Such programs may pose greater challenges for student participation, as they require a strong extracurricular time commitment. The present study examined the effects of mindfulness training incorporated into a semester-long college seminar dedicated to both practical learning of mindfulness skills and scientific understanding of mindfulness theory, based on the evidence-based Learning to BREATHE (L2B) curriculum. In a quasi-experimental design, first-year undergraduate students in the mindfulness seminar were compared with a control group enrolled in a positive psychology and study skills seminar. Students in the mindfulness seminar exhibited more improvement in satisfaction with life and trait mindfulness, as well as less anxiety; in contrast, no differences were observed in cognitive function. These results demonstrate the feasibility and potential psychological benefits of integrating mindfulness training into standard college curriculum.
\end{abstract}

Keywords: Mindfulness, college students, freshman, psychological well-being, cognitive function 


\section{Introduction}

For many individuals, the transition to college is often seen as the first stage of adulthood, with students beginning to pursue future career interests, and engaging in a wider range of social interactions involving more diverse and complex communities. Moreover, this critical period often takes place in a completely unfamiliar environment, with increased challenges from academic work, social relationships, and financial responsibility (Brougham, Zail, Mendoza, \& Miller, 2009; Kadison \& DiGeronimo, 2004). Consequently, the college transition period is frequently associated with increased stress, compromised mental health, and problematic behaviors, such as excessive drinking and other severe forms of substance abuse (Knight et al., 2002; Zivin, Eisenberg, Gollust, \& Golberstein, 2009). A recent national report from college counseling centers corroborate these patterns, showing a high prevalence and severity of psychological health problems among college students across more than 600 colleges and universities (LeViness, Bershad, \& Gorman, 2017). Anxiety is the most prevalent disorder reported (48.2\%), closely followed by stress-related health complaints (39.1\%) and depression $(34.5 \%)$. More alarmingly, this pattern has been persistent and increasingly severe over the past decade (Zivin et al., 2009; LeViness, Bershad, \& Gorman, 2017), indicating a pressing need to develop and provide effective prevention and intervention programs within higher education to target these detrimental psychological health problems associated with college transition and experiences.

The most deleterious aspect of mental health issues in college students, aside from the constant emotional turmoil, has to do with the widespread impact they have on students' academic work and extracurricular activities, including loss of productivity, suboptimal cognitive function, and increased social isolation, which are commonly observed phenomena among 
individuals suffering from poor mental health (Brougham et al., 2004; Prince et al., 2007). For college students, emotional disturbances can significantly undermine individual well-being (Struthers, Perry, \& Menec, 2000), making them unable to cope with existing challenges, as well as potential upcoming stressors that may arise as a result of their already compromised psychological, cognitive, and social functioning. Therefore, in addition to traditional on-campus mental health services, dedicated intervention programs from academic institutions are needed to prevent and ameliorate such systemic challenges, and instead enhance students' wellbeing during this important transition. If relevant programs of this type could be integrated into the standard educational curriculum, it could potentially provide a more 'universal' solution to the growing mental health and wellness needs of incoming students.

Accumulating evidence over the past two decades has suggested mindfulness training may serve as a promising intervention for promoting psychological wellbeing, particularly for reducing stress and ameliorating symptoms of anxiety and depression (Gu, Strauss, Bond, \& Cavanagh, 2015; Hofmann, Sawyer, Witt, \& Oh, 2010). A recent meta-analysis focusing on the effects of mindfulness-based interventions in post-secondary students also suggests similar psychological benefits in students with mental health related complaints (Halladay et al., 2018). Concurrently, mindfulness training may also result in cognitive benefits, in domains such as attention, working memory, and other aspects of executive function (Chiesa, Catati, \& Serretti, 2011; Lao, Kissane, \& Meadows, 2016). As a secular psychological intervention originally adapted from traditional Buddhist practices, mindfulness training focuses on promoting present moment attention and awareness, with a nonjudgmental and accepting attitude, which could help individuals to effectively detect and regulate thoughts, emotions, or sensations that may arise at any given moment (Hölzel et al., 2011). However, standardized mindfulness training programs 
including the most researched programs Mindfulness-based Stress Reduction (MBSR) (KabatZinn, 1990) and Mindfulness-based Cognitive Therapy (MBCT) (Segal, Williams, \& Teasdale, 2002) have predominately been designed to accommodate characteristics of general adult populations. Consequently, the curriculum is not specifically adapted to meet the needs of college students. Furthermore, these well-established programs are not designed to be wellintegrated into a college curriculum, since they require a substantial time commitment outside of regular school hours and environment (Halladay et al., 2018). These requirements may also make it difficult for students to participate and access these potentially useful resources. Similarly, even in studies that have examined mindfulness training programs specifically designed for college populations (e.g. Greeson et al., 2014; Jain et al., 2007; Mrazek et al., 2013; Oman, Shapiro, Thoresen, Plante, \& Flinders, 2008), the training is typically offered as an extracurricular option that is completely separated from standard college curriculum.

Until recently, only preliminary yet encouraging efforts have been made to better incorporate mindfulness training into college setting. One study by Morrison and colleagues (2014) administered a 7-week mindfulness training to undergraduate students, by incorporating mindfulness practices into an introductory college seminar. The researchers found that students in the mindfulness seminar group showed greater improvement in sustained attention after seminar completion, relative to those in a wait-list control group, suggesting the feasibility of integrating mindfulness training into the college curriculum, as well as the effectiveness of such approaches in improving cognitive outcomes. Relatedly, Dvořáková and colleagues (2017) provided a 6-week mindfulness training based on an evidence-based Learning To BREATHE program (Broderick, 2013), adapted specifically for college students. Incoming freshmen who lived in residential halls were recruited to this on-site mindfulness program, allowing them to 
easily participate in mindfulness practices that could facilitate stress reduction and cultivation of emotion regulation skills. At the end of the program, students exhibited significant increase in life satisfaction, and decrease in symptoms of depression and anxiety compared to a wait-list control group, indicating that a mindfulness-based program tailored to the characteristics and needs of college students within the familiar college environment can effectively improve their psychological well-being.

While these two lines of evidence are promising in demonstrating the effectiveness of integrating mindfulness training into the college curriculum and setting, the use of wait-list control groups in both studies poses a methodological limitation. Extraneous factors such as intellectual development, knowledge accumulation, and life experiences during the course of an academic semester may contribute to the observed enhancement in psychological and cognitive well-being. A research design with an active control group would mitigate these confounds. A further limitation of the programs described above is that they were specialized courses presented to students as extra-curricular options. A more seamless approach would be to integrate mindfulness training as part of standard first-year curricular offerings, for which students could receive academic course credit.

Therefore, to extend and build upon these previous findings, the current study aimed to incorporate mindfulness training into the first-year college curriculum. An introductory mindfulness seminar was developed similar to the one provided in the study by Morrison and colleagues, but utilizing and adapting the evidence-based mindfulness program Learning to BREATHE (Broderick, 2013; Metz et al., 2013) as the core curriculum (Dvořáková et al., 2017). We evaluated the feasibility and efficacy of such seminar in promoting psychological health and cognitive function in first-year undergraduate students through a quasi-experimental design, in 
which students were self-enrolled in the seminar, instead of participation through randomized assignment. An introductory psychology seminar that fostered personal growth and development in college students was selected as an active control group, allowing for a more rigorous comparison of training effects. It is important to note that students in both seminars were selfselected to be in one of these courses and thus share a common interest in enhancing their psychological well-being and transition into college; consequently, any selection biases should be mitigated when comparing the two groups. We hypothesized that both psychological wellbeing and cognitive function would improve at the end of semester only for the mindfulness seminar students, while no significant changes would be observed for students in the control psychology seminar. Additionally, we examined potential gender differences in response to mindfulness training in our analysis, as one recent report in college students suggested that women tend to benefit more than men in terms of negative affect, mindfulness, and selfcompassion following mindfulness training (Rojiani et al., 2017).

\section{Methods}

\section{Participants}

Participants were first-year undergraduate students, who self-enrolled in a 1-hour credit seminar class occurring during Fall 2016, Fall 2017, or Fall 2018 academic semesters. The experimental group consisted of students (Mean age $=18.28, S D=0.45$ ) who registered for the "Mindfulness: Science and Practice" $(\mathrm{N}=46)$. Females comprised $60.9 \%$ of students in this group. The control group (Mean age $=18.05, S D=0.23)$ consisted of students $(73.9 \%$ females $)$ who registered for an introductory psychology seminar in Fall 2016: the "Psychology of Young Adulthood: College Years" $(\mathrm{N}=111)$. To increase responsiveness, participants in the control 
group received compensation $(\$ 10)$ at baseline, as well as at the end of semester for completing a battery of cognitive assessment ( $\$ 10$ plus a $\$ 5$ bonus). However, they did not receive any form of compensation for completing questionnaire assessment, which was a part of their class requirement. Students in the mindfulness seminar did not receive any form of compensation, since completion of both the questionnaires and cognitive tasks were required for the class and discussed as part of the educational experience. All protocols were approved by the Institutional Review Board. Informed consent was obtained from all participants.

\section{Procedure}

Both classes met on a one-time-per-week basis (14 sessions in total) and were each led by a primary instructor. The mindfulness seminar instructor had over 8 years maintaining a regular mindfulness practice, including participation in 6 multi-day intensive retreats, and further received direct guidance from the L2B program developer with regard to program implementation and adaptation. For the mindfulness class, the seminar took place at a residential hall after 5PM, whereas the psychology class was held in a regular classroom setting during daytime hours. At baseline and at the end of the semester (two time points), self-report questionnaires were collected in the Research Electronic Data Capture program (REDCap; a set of electronic data capture tools hosted at Washington University). A battery of cognitive tasks was administered through the Inquisit Web software program (developed by the Millisecond Company, and consisting of a prebuilt library of psychometric assessments for cognitive, neuropsychological, and online research). It should be noted that students did not complete these cognitive tasks or questionnaires in a laboratory setting, but rather in a more natural setting during their leisure time. 


\section{Intervention}

\section{Mindfulness Seminar Curriculum}

The overarching goal of the mindfulness seminar was to introduce students to mindfulness practices as well as current scientific research in this area. Thus, the curriculum was divided into two parts: practicing mindfulness through direct experiential activities, and learning and understanding the science of mindfulness. The practice component of the course consisted of learning about and practicing different mindfulness meditation techniques and also engaging in activities and exercises that promoted mindful awareness, such as mindfulness eating, walking, and drawing. The science component of the course mainly involved reading and discussing assigned research articles and findings related to mindfulness. Mindfulness exercises and activities were primarily based on an evidence-based curriculum called Learning to BREATHE (L2B), which has been shown to improve psychological well-being primarily in adolescents (Bluth et al., 2016; Broderick, 2013; Felver et al., 2018; Metz et al., 2013; Shomaker et al., 2017), but also more recently in first-year college students (Dvořáková et al., 2017; Mahfouz et al., 2018).

Mindfulness techniques that were taught during class-time practice sessions included breath focus, body scanning, loving-kindness, and open monitoring of thoughts, feelings and bodily sensations. Students were strongly encouraged, but not required, to practice outside of class time. Some adaptation was made to the L2B curriculum in consultation with developers of the L2B program at Penn State University. Each one-hour class session began with a 5-10minute mindfulness practice (either orally guided by the instructor or through taped audio instructions). Subsequently, students either discussed key findings of research articles or divided into groups to engage in mindfulness-related activities and exercises, and to share their own 
experiences of mindfulness practices with rest of the class. The class session also concluded with a 5-10 mindfulness meditation (except in cases in which time ran short). During the first three weeks of the class, students met twice weekly to learn and consolidate their mindfulness techniques (discussion of research articles was not involved); the rest of the semester (8 weeks) required only one meeting per week. A detailed breakdown of each class session (14 sessions in total) can be found in the Supplementary Material. Outside of the classroom, students were also required to keep a daily log of their practice activities and were encouraged to practice regularly.

\section{Psychology Seminar Curriculum}

This one-hour course (titled Psychology of Young Adulthood) met once a week over the span of 14 weeks, and has been taught for many years at Washington University to first-year undergraduate students. The major aims were to foster psychological growth and development for students specifically during their college years, and to discuss topics relevant to the developmental, social, personal, and cognitive issues that confront young adults during this time period. In some ways, this class can be considered to be analogous to a positive psychology course, which nicely served as an appropriate comparison for the present study, since the conceptual emphasis was similar, while the didactic approach was fairly different and complementary. The class was mainly taught in lecture style, with in-class discussion and activities. In particular, empirically supported strategies for promoting psychological growth and development were among the top emphases of this course. Ultimately, the goal of the course was to provide students with relevant knowledge that could be used to facilitate academic success, personal development, and a more rewarding social and academic experience over the course of college and beyond. 


\section{Assessments}

\section{$\underline{\text { Self-report Questionnaires }}$}

Trait Mindfulness. The Mindful Awareness Attention Scale (MAAS) was used to assess individual differences in trait mindfulness, which is the ability to pay attention and be openly aware of the present moment in a calm and non-judgmental way. The questionnaire has 15 Likert-scale items that range from 1 (Almost Always) to 6 (Almost Never), tapping into the degree to which an individual goes about daily activity in a mindful vs. mindless way. The MAAS has been validated previously in numerous studies and populations as a reliable measure of trait mindfulness (Cronbach's $\alpha=.89-.93$; test-retest $r=.35-.52$ ) (Black, Sussman, Johnson, \& Milam, 2012; Brown \& Ryan, 2003; Van Dam, Earleywine, \& Borders, 2010).

Self-Compassion. The Self-Compassion Scale (SCS) contains 12 items that measures one's tendency to be accepting, understanding, and caring towards oneself when facing failures, struggles, and negative emotions in life (Neff, 2003; Raes et al., 2011). Scores for each item can range from 1 (Almost Never) to 5 (Almost Always). The SCS has been shown to have high testretest reliability across all of its subscales $(r>.80)$ (Neff, 2003).

Self-Control. The 13-item Self-Control Scale (SCTRL) assesses the ability of people to control their own behavior and actions in relative autonomy without getting hampered by external distraction and impulses (Tangney, Baumeister, \& Boone, 2004). A Likert scale from 1 (Not at all) to 5 (Very much) was used to rate each described statement. It has also demonstrated good internal consistency and reliability (Cronbach's $\alpha=.83-.85$; test-retest $r=.87$ ) (Tangney et al., 2004).

Satisfaction with Life. The Satisfaction with Life scale measures one's cognitive perception and judgment of his or her life with 5 brief questions and is shown to have high 
internal consistency and reliability with a .87 Cronbach's $\alpha$ and a .82 test-retest reliability (Diener et al., 1985). Sample questions include "If I could do my life over, I would change almost nothing", and "The conditions of my life are excellent". A Likert scale from 1 (Strongly Disagree) to 7 (Strongly Agree) was used.

Sleeping Quality. The Pittsburgh Sleep Quality Index is a subjective questionnaire that assesses 7 aspects of sleep over the past one month: sleep quality, sleep latency, sleep duration, sleep efficiency, sleep disturbances, use of sleeping medication, and daytime dysfunction (Buysse et al., 1989). Each of these subscales ranges from 1 (0 to 3 ) and are usually summed together to get a total score. Higher scores indicate poorer sleeping quality. The PSQI has been previously shown in multiple reports to have good reliability (Cronbach's $\alpha>.70$; testretest $r>.70)$.

Anxiety. The Generalized Anxiety Disorder Scale (GAD) is a 7-item measure designed to assess the frequency of experiencing anxiety-related symptoms such as worrying and feeling restless in the previous two weeks (Spitzer et al., 2006). Item score ranges from 0 (Not at all) to 3 (Nearly every day). The GAD has a .92 Cronbach's $\alpha$ and a .83 test-retest reliability. This scale was administered for students in Fall 2016 seminars. For those in Fall 2017 or Fall 2018 seminar, the State-Trait Anxiety Inventory (STAI) was used to measure anxiety. STAI is a 40-item measure commonly used in clinical setting to diagnose anxiety, which includes 20 items for assessing trait anxiety (how people generally feel) and 20 items for assessing state anxiety (how people feel right at this moment) (Spielberger, Gorsuch, Lushene, Vagg, \& Jacobs, 1983). Item score ranges from 1 (Not at all) to 4 (Very much so). The scale has also been shown to be highly reliable across different populations (Cronbach's $\alpha=.86-.95)$. 
Depression. The Patient Health Questionnaire (PHQ) was used to assess depressive symptoms such as anhedonia and feeling down during the previous two weeks (Kroenke \& Spitzer, 2002). Each question was rated from 0 (Not At all) to 3 (Nearly every day). This 8-item questionnaire has been commonly used as a screening scale for depression and has shown good reliability (Cronbach's $\alpha=.86-.89$; test-retest $r=.84$ ).

Practice Logs. Daily logs were provided to students in the mindfulness seminar. Students were asked to record their daily mindfulness practices and related activities, as well as the corresponding duration. If they did not practice, they were asked to record zero. Typical mindfulness techniques include breath counting, loving kindness, focused attention, or other well-known practices taught in class, while mindfulness activities include daily activities such as eating and exercising, during which students reported to have engaged in them with intentional mindfulness.

\section{$\underline{\text { Cognitive Tasks }}$}

Attention Network Test (ANT): This task is thought to measure the function of three core attention networks (alerting, orienting, executive control) (Fan et al., 2002). Specifically, participants were presented with arrows either above or below a fixation cross shown on a computer screen and asked to determine the pointing direction of the center arrow. The task has three flanker conditions: 1) neutral, when the center arrow is not flanked by arrows but by straight lines, 2) congruent, when the center arrow is flanked by arrows pointing to the same direction, and 3) incongruent, when the center arrow is flanked by arrows pointing to the opposite direction. In addition, there were four cue conditions (no cue, center cue, double cue, spatial cue) that may alert participants that targets are about to come on screen and potentially 
where on the screen (above or below the cross). The center cue and double cue indicated targets are about to appear on screen, but did not provide any location information, whereas spatial cues indicated where arrows are about to show up on screen. The frequency of each cue and flanker condition appeared in trials was equal. The task comprised one block of 24 practice trials with feedback and two additional test blocks of 64 trials. Reaction time (RT) and accuracy were both recorded for later calculation of the efficiency of three attention networks. Specifically, these efficiencies are defined as the following: alerting effect=RT no cue - RT center cue, orienting effect=RT center cue - RT spatial cue, conflict effect=RT incongruent - RT congruent.

Sustained Attention to Response Task (SART): The SART is a type of Go/NoGo task in which the nogo stimulus is presented very infrequently, thereby leading to an autonomic tendency to press the go key if sustained attention is not present to detect and monitor responding (Robertson et al., 1997). In this task, participants were presented with a single digit 1-9 in the middle of the screen in varying font sizes. The digit then disappeared and was replaced by a circle with an X. Next, participants were asked to press a predefined key if any digit other than 3 was presented and to withhold a response if digit 3 was presented. There were 225 trials and the digit 3 appeared in $11 \%$ (25) of the trials. Reaction time (RT) and accuracy were both recorded for later calculation of percent of errors in nogo trials, commonly referred to as commission errors, and RT variability in correct go trials, which is the coefficient of variability in RT (CVRT), calculated by dividing the RT standard deviation by the mean RT.

Operation Span Task (OSPAN): The OSPAN is a standard task for measuring a form of working memory span by asking participant to perform simple mathematical operations while trying to remember the order of a list of letters (Conway et al., 2005). In particular, participants 
were presented with a sequence ranging from 3 to 7 letters that need to be recalled at the end.

The presentation of each letter on screen was preceded by a math problem (““ $3 * 4-8=$ ?”)

followed by a proposed solution (“5”), and participants needed to indicate if this answer is correct by clicking "True" or "False". After presentation of all letters in the sequence, recall was assessed by asking participants to select, from a letter matrix, the letters that were originally presented, in the correct order of presentation. Participants first practiced 3 trials in the practice session, followed by 15 trials in the test session. The importance of accuracy in math calculation and recall order was stressed throughout the task by immediately showing the percentage of correct responses following each math problem and recalled set. Participants were also told beforehand that they need to solve these math problems as quickly and accurately as possible, and to maintain at least $85 \%$ of accuracy, otherwise their data could not be used for analyses. The sum of all correctly recalled sets was recorded, as well as the total number of letters recalled in the correct position.

\section{Data Analysis}

All questionnaires and cognitive task measures were scored and calculated based on published scoring guides and past literature, which can be found in references stated above. Data were visually inspected for any outliers and violation of normality assumptions. Pairwise deletion was used for missing data and outliers were identified and removed from further analyses if values were two standard deviations above or below the mean.

Independent samples t-tests were conducted for all questionnaires and task measures to examine if there were any baseline differences between the mindfulness seminar and the control seminar. Significant baseline difference $(t=2.25, p<0.05)$ was only found in PHQ (depression) 
such that students in the mindfulness seminar had slightly more depressive symptoms than those in the control seminar. There was no significant baseline difference in any of the measures between women and men for the control group, while women in the mindfulness group had slightly higher levels of self-control $(t=2.07, p<0.05)$.

Our primary goal was to test for any changes in cognitive task and self-report measures from pre-test (beginning of class) to post-test (end of class) for both groups, then compare these changes between groups. Typically, repeated measures analysis of variance (RM-ANOVA) is conducted to examine between and within group differences for this type of design. However, given the smaller sample size of the mindfulness seminar, as well as considerable differences in the sizes of the two groups, conventional tests of significance are less meaningful and less appropriate for the present study. Thus, for all behavioral assessments, we report and interpret the results in terms of effect sizes using Cohen's $d_{z}$ for both groups. Regardless, standard RMANOVA approaches were performed, and results can be found in the Supplementary Material. A descriptive statistics table (Table 1) is provided below for all measures from both groups. It should also be noted that different sample sizes across tasks were due to failure of some students to complete certain tasks.

\section{INSERT TABLE 1 HERE}

\section{Results}

Here, we present the more intuitive Cohen's $d_{z}$, an effect size that is commonly used in paired t-tests to compare changes in behavioral outcomes from baseline to conclusion of the class between these two groups. For ease of interpretation, we modified the direction of signs, such 
that positive values of effect sizes indicate better cognitive function, faster reaction times, and greater psychological well-being at the post-test assessment relative to pre-test, whereas negative signs indicate the opposite. P-values for paired t-tests are also included along with effect sizes.

\section{Psychological Wellbeing}

Participants in the mindfulness seminar exhibited overall positive changes in most aspects of psychological well-being, consistent with previously observed benefits. Specifically, at post-assessment, students in mindfulness seminar had small to moderate improvement in trait mindfulness (Cohen's $\left.d_{\mathrm{z}}=0.328, \mathrm{p}<0.05\right)$, symptoms of general anxiety (Cohen's $d_{\mathrm{z}}=0.839$, $\mathrm{p}<0.001)$, state anxiety (Cohen's $\left.d_{\mathrm{z}}=0.318, \mathrm{p}>0.05\right)$, trait anxiety (Cohen's $d_{\mathrm{z}}=0.162, \mathrm{p}>0.05$ ), satisfaction with life (Cohen's $d_{\mathrm{z}}=0.329, \mathrm{p}<0.05$ ), and self-compassion (Cohen's $d_{\mathrm{z}}=0.288$, p>0.05), compared to the control group. Interestingly, as shown in Figure 1, participants in both groups reported less self-control, poorer sleeping quality and more depressive symptoms (PHQ) at post-assessment. Nevertheless, this pattern may not be surprising as elaborated in the Discussion. Finally, as a secondary analysis, we also examined potential gender differences in the extent of improvement for indexes of psychological well-being, but no significant gender differences were detected as tested by RM-ANOVA for both groups.

\section{INSERT FIGURE 1 HERE}

Fig.1 Effect sizes of psychological wellbeing indexes for both groups. Positive effect sizes suggest improvement in psychological health, whereas negative effect sizes indicate the opposite trend. 


\section{Cognitive Measures}

Compared to baseline, students in both groups exhibited small improvement in two indices of the sustained attention: commission errors and CVRT, with the control group showing slightly larger effect sizes than the mindfulness group. Similarly, small to moderate improvement was found in the efficiency of orienting attention network for mindfulness group (Cohen's $d_{\mathrm{z}}=$ 0.262, $\mathrm{p}>0.05$ ), while no change was detected in control group. Both groups exhibited small to moderate improvement in executive attention network, with the control group (Cohen's $\left.d_{\mathrm{z}}=0.836, \mathrm{p}<0.05\right)$ showing a larger effect size than the mindfulness group (Cohen's $d_{\mathrm{z}}=0.322$, $\mathrm{p}>0.05)$. However, an exception was found in alerting attention work, for which a small negative effect size was observed for mindfulness group, indicating a reduction in alerting network efficiency (Cohen's $\left.d_{\mathrm{z}}=-0.318, \mathrm{p}>0.05\right)$, whereas control group exhibited a small to moderate improvement in the same measure (Cohen's $\left.d_{\mathrm{z}}=0.615, \mathrm{p}<0.05\right)$. Figure 2 below illustrates effect sizes of all cognitive measures for both groups.

\section{INSERT FIGURE 2 HERE}

Fig.2 Effect sizes of cognitive measures for both groups. Positive effect sizes suggest improvement in cognitive performance, whereas negative effect sizes indicate the opposite trend.

\section{Practice Time}

Participants in the mindfulness seminar were strongly encouraged to practice regularly, and were required to keep a log recording the duration of mindfulness-related activities (e.g., eating, walking) and formal practice (e.g., breath focus, compassion). This encouragement was 
successful, as students reporting engaging in approximately 45 minutes of practice per week (outside of the classroom), but with quite a lot of individual variability (activities: $M=16.77$, $S D=23.59$; techniques: $M=28.02, S D=15.44)$. Consequently, we tested whether this variation in duration correlated with any of our dependent measures. However, none of the correlations reached statistical significance $(\mathrm{p}>0.05$, uncorrected $)$.

\section{Discussion}

We employed a quasi-experimental design comparing mindfulness training with an active control group to examine the feasibility and effectiveness of incorporating mindfulness training into standard college curriculum offerings. In terms of self-reported measures of psychological well-being, the findings were somewhat consistent with prior reports, indicating moderate to large positive effect on anxiety, and small to moderate effects on trait mindfulness, selfcompassion and satisfaction with life. However, somewhat inconsistent with a number of prior reports, we did not find evidence of cognitive function being differentially enhanced by mindfulness training. Although improvements in some measures were observed (e.g., executive attention), these were present in both groups, and thus could not be differentiated from general practice (or other common) effects. We next discuss these effects further with regard to the prior literature.

First-year college students that enrolled in the mindfulness seminar showed evidence of improvements in mindfulness capacity and life satisfaction, whereas students in control group did not have a similar level of improvement in these indexes. Self-report anxiety symptoms were reduced in mindfulness group compared to control group, which is consistent with a previous 
study that showed improvement in anxiety after mindfulness training, using the same curriculum (Dvořáková et al., 2017). Surprisingly, poorer sleep quality and more depressive symptoms at post-assessment were observed for both groups, contrary to what we had hypothesized based on prior literature. However, this could possibly be due to the fact that our post-assessment was conducted towards the end of semester during finals period, a time that students were likely to have disrupted patterns of sleep, leading to possible depressive symptoms. This interpretation is consistent with the finding that both groups showed the same patterns. Moreover, it is worth noting that students in mindfulness group had less increase in depressive symptoms than those in control group, suggesting that mindfulness practices may potentially have protective effects against stress-related depressive symptoms during academic semester, prepare students to cope with stress and have productive response to stressors (Dvořáková, Greenberg, \& Roeser, 2018). This could explain why students in mindfulness group, even though experiencing similar levels of stress as their peers in control group during the finals period, seemed to be more resilient in the face of challenges as indicated by fewer self-reported depressive symptoms. Lastly, selfcontrol also showed decline in both groups, which was also unexpected, since mindfulness training has been theorized and found to enhance self-control capacity as measured by objective cognitive tasks (Tang et al., 2007). However, in this study the measure of self-control was subjective, so it is possible that students' perception of their own self-control ability may not have been accurate. Furthermore, another plausible interpretation is that students became more aware of their self-control abilities (in both groups, since the concept of self-control was a focus of both), resulting in a completely different perception of self-control relative to their original perception at the beginning of the semester. 
In terms of cognitive measures, the results did not provide strong evidence for differential enhancement of mindfulness on attentional efficiency, reduced mind-wandering, or working memory. Regarding attention efficiencies, as assessed by the attention network test (ANT), the observed patterns were somewhat contrary to what has been found in prior studies (Jha et al., 2007; Tang et al., 2007; van den Hurk et al., 2010), where mindfulness training typically induced stronger changes in executive attention and orienting network efficiencies at post-assessment. However, the current results may not be that surprising, given that the amount of training students received in the present study is not comparable to previous studies that had a greater total number of hours of mindfulness training. Yet the lack of positive benefit observed in mindfulness group for alerting network efficiency does stand in stark contrast to previous studies that showed enhanced function after mindfulness training (Tang et al., 2007; Jha et al., 2007).

Another surprising aspect of the findings was that two indices of sustained attention in the SART task, as well as executive network efficiency measured by the ANT task, though showing improvement in mindfulness group, actually exhibited larger positive effects in the control group. These two indices of SART are thought to reflect the presence of mind-wandering (Robertson et al., 1997; Bastian \& Sackur, 2013). At least one prior report has also shown a strong relationship between reductions in mind-wandering and increased working memory function (Mrazek, Smallwood, \& Schooler, 2012), so the weaker findings in both measures in the current study may also be related.

There are several additional possible explanations that might account for these deviant patterns in cognitive function. First of all, a relatively non-standard aspect of the class design was that students did not complete the cognitive tasks within a standard laboratory setting. Instead, tasks were performed in an on-line format, on students' own time, and in an 
unmonitored manner. Consequently, it is possible that testing environments were sub-optimal, in terms of time, noise, and distraction potential, reducing data quality. Additionally, for students in the control group, data analyses were only conducted on participants who completed the entire cognitive task battery, which means that those participants who completed just one or two tasks were excluded from analyses. The reason for this strategy was due to our compensation scheme, such that participants were only compensated if they completed all tasks; consequently, we were required not to keep data from participants that were not compensated. Therefore, it is plausible that those who persisted and finished all cognitive tasks may have had inherent differences in their level of motivation, persistence, and cognitive ability, which could all potentially contribute to the observed task outcomes to some extent. Conversely, the assessments of self-reported psychological well-being were likely less affected by these abovementioned extraneous factors, since both classes had to complete the self-report questionnaires as part of their class requirement. Moreover, questionnaire responses are less likely to be vulnerable to environmental distractions and noise than cognitive tasks.

Yet a final point is that the effects of mindfulness training on cognitive function in healthy adults may actually be less reliable and consistent than it seems from a more cursory read of the prior literature. Indeed, more recent literature reviews have found that mindfulness effects on attention and executive control measures are actually fairly inconsistent (Lao et al., 2016). Thus, it may be the case that the observed effects in cognitive task measures are not so surprising, especially when considering that all students had above-average cognitive functioning (i.e. working memory capacity was between the $67^{\text {th }}$ to $75^{\text {th }}$ percentile on average) even at baseline (i.e. all participants were students enrolled at a highly selective private university). Likewise, it is worth noting that the sample size was somewhat small, particularly for the 
cognitive tasks for both groups, due to some students in mindfulness group not completing the entire task set and low responsive rate from the control group (for whom task completion was optional). Because the present study was primarily conducted as a pilot investigation, sample size was inevitably smaller than what would otherwise be desirable. Consequently, statistical power was low for detecting moderate effects and subtle differences between the two groups.

\section{Conclusions}

First-year college students belong to a special population that is constantly facing new challenges from the external environment. As they embark on the first journey into adulthood, college students require not only academic support from their primary institutions, but also psychological support that can help strengthening their resilience in the face of difficulties and improve their psychological well-being during this sensitive period of time where emotional distress is common. Our study provides some support for the proposition that incorporating mindfulness training into a standard college curriculum and setting is both feasible and potentially effective for promoting well-being. It provides students with convenient access to resources that are tailored specifically to their needs and characteristics. Consequently, this approach could be a promising one for promoting mental health in college population. Although cognitive benefits were rather small and mixed, there was an overall improvement in measures of psychological health for students who underwent mindfulness training. Additional data are needed in order to more conclusively determine the size of observed effects and confirm their statistical reliability. Yet the current findings do already point to the potential positive effects of mindfulness training on psychological well-being in first-year students, and as such, warrant further larger-scale investigation. 


\section{References}

Bastian, M., \& Sackur, J. (2013). Mind wandering at the fingertips: automatic parsing of subjective states based on response time variability. Frontiers in psychology, 4, 573.

Bluth, K., Campo, R. A., Pruteanu-Malinici, S., Reams, A., Mullarkey, M., \& Broderick, P. C. (2016). A school-based mindfulness pilot study for ethnically diverse at-risk adolescents. Mindfulness, 7(1), 90-104.

Broderick, P. C. (2013). Learning to breathe: A mindfulness curriculum for adolescents to cultivate emotion regulation, attention, and performance. New Harbinger Publications.

Brougham, R. R., Zail, C. M., Mendoza, C. M., \& Miller, J. R. (2009). Stress, sex differences, and coping strategies among college students. Current psychology, 28(2), 85-97.

Brown, K. W., \& Ryan, R. M. (2003). The benefits of being present: mindfulness and its role in psychological well-being. Journal of personality and social psychology, 84(4), 822.

Buysse, D. J., Reynolds III, C. F., Monk, T. H., Berman, S. R., \& Kupfer, D. J. (1989). The Pittsburgh Sleep Quality Index: a new instrument for psychiatric practice and research. Psychiatry research, 28(2), 193-213.

Chiesa, A., Calati, R., \& Serretti, A. (2011). Does mindfulness training improve cognitive abilities? A systematic review of neuropsychological findings. Clinical psychology review, 31(3), 449-464.

Conway, A. R., Kane, M. J., Bunting, M. F., Hambrick, D. Z., Wilhelm, O., \& Engle, R. W. (2005). Working memory span tasks: A methodological review and user's guide. Psychonomic bulletin \& review, 12(5), 769-786.

Diener, E. D., Emmons, R. A., Larsen, R. J., \& Griffin, S. (1985). The satisfaction with life scale. Journal of personality assessment, 49(1), 71-75.

Dvořáková, K., Greenberg, M. T., \& Roeser, R. W. (2018). On the Role of Mindfulness and Compassion Skills in Students' Coping, Well-being and Development across the Transition to College: A Conceptual Analysis. Stress and Health.

Dvořáková, K., Kishida, M., Li, J., Elavsky, S., Broderick, P. C., Agrusti, M. R., \& Greenberg, M. T. (2017). Promoting healthy transition to college through mindfulness training with firstyear college students: Pilot randomized controlled trial. Journal of American College Health, 65(4), 259-267.

Fan, J., McCandliss, B. D., Sommer, T., Raz, A., \& Posner, M. I. (2002). Testing the efficiency and independence of attentional networks. Journal of cognitive neuroscience, 14(3), 340-347.

Felver, J. C., Clawson, A. J., Morton, M. L., Brier-Kennedy, E., Janack, P., \& DiFlorio, R. A. (2018). School-based mindfulness intervention supports adolescent resiliency: A randomized controlled pilot study. International Journal of School \& Educational Psychology, 1-12. 
Greeson, J. M., Juberg, M. K., Maytan, M., James, K., \& Rogers, H. (2014). A randomized controlled trial of Koru: a mindfulness program for college students and other emerging adults. Journal of American College Health, 62(4), 222-233.

Gu, J., Strauss, C., Bond, R., \& Cavanagh, K. (2015). How do mindfulness-based cognitive therapy and mindfulness-based stress reduction improve mental health and wellbeing? A systematic review and meta-analysis of mediation studies. Clinical psychology review, 37, 1-12.

Halladay, J. E., Dawdy, J. L., McNamara, I. F., Chen, A. J., Vitoroulis, I., McInnes, N., \& Munn, C. (2018). Mindfulness for the Mental Health and Well-Being of Post-Secondary Students: A Systematic Review and Meta-Analysis. Mindfulness, 1-18.

Hofmann, S. G., Sawyer, A. T., Witt, A. A., \& Oh, D. (2010). The effect of mindfulness-based therapy on anxiety and depression: A meta-analytic review. Journal of consulting and clinical psychology, 78(2), 169.

Hölzel, B. K., Lazar, S. W., Gard, T., Schuman-Olivier, Z., Vago, D. R., \& Ott, U. (2011). How does mindfulness meditation work? Proposing mechanisms of action from a conceptual and neural perspective. Perspectives on psychological science, 6(6), 537-559.

Jain, S., Shapiro, S. L., Swanick, S., Roesch, S. C., Mills, P. J., Bell, I., \& Schwartz, G. E. (2007). A randomized controlled trial of mindfulness meditation versus relaxation training: effects on distress, positive states of mind, rumination, and distraction. Annals of behavioral medicine, 33(1), 11-21.

Jha, A. P., Krompinger, J., \& Baime, M. J. (2007). Mindfulness training modifies subsystems of attention. Cognitive, Affective, \& Behavioral Neuroscience, 7(2), 109-119.

Kabat-Zinn, J. (1990). Full catastrophe living: The program of the stress reduction clinic at the University of Massachusetts Medical Center.

Kadison, R., \& DiGeronimo, T. F. (2004). College of the overwhelmed: The campus mental health crisis and what to do about it. Jossey-Bass.

Knight, J. R., Wechsler, H., Kuo, M., Seibring, M., Weitzman, E. R., \& Schuckit, M. A. (2002). Alcohol abuse and dependence among US college students. Journal of studies on alcohol, 63(3), 263-270.

Kroenke, K., \& Spitzer, R. L. (2002). The PHQ-9: a new depression diagnostic and severity measure. Psychiatric annals, 32(9), 509-515.

Lao, S. A., Kissane, D., \& Meadows, G. (2016). Cognitive effects of MBSR/MBCT: a systematic review of neuropsychological outcomes. Consciousness and cognition, 45, 109-123.

LeViness, P., Bershad, C., \& Gorman, K. (2017). The Association for University and College Counseling Center Directors Annual Survey.

Mahfouz, J., Levitan, J., Schussler, D., Broderick, T., Dvorakova, K., Argusti, M., \& Greenberg, M. (2018). Ensuring College Student Success Through Mindfulness-Based Classes: Just Breathe. College Student Affairs Journal, 36(1), 1-16. 
Metz, S. M., Frank, J. L., Reibel, D., Cantrell, T., Sanders, R., \& Broderick, P. C. (2013). The effectiveness of the learning to BREATHE program on adolescent emotion regulation. Research in Human Development, 10(3), 252-272.

Morrison, A. B., Goolsarran, M., Rogers, S. L., \& Jha, A. P. (2013). Taming a wandering attention: short-form mindfulness training in student cohorts. Frontiers in Human Neuroscience, 7.

Mrazek, M. D., Franklin, M. S., Phillips, D. T., Baird, B., \& Schooler, J. W. (2013). Mindfulness training improves working memory capacity and GRE performance while reducing mind wandering. Psychological science, 24(5), 776-781.

Mrazek, M. D., Smallwood, J., \& Schooler, J. W. (2012). Mindfulness and mind-wandering: finding convergence through opposing constructs. Emotion, 12(3), 442.

Neff, K. D. (2003). Development and validation of a scale to measure self-compassion. Self and Identity, 2, 223-250.

Oman, D., Shapiro, S. L., Thoresen, C. E., Plante, T. G., \& Flinders, T. (2008). Meditation lowers stress and supports forgiveness among college students: A randomized controlled trial. Journal of american college health, 56(5), 569-578.

Prince, M., Patel, V., Saxena, S., Maj, M., Maselko, J., Phillips, M. R., \& Rahman, A. (2007). No health without mental health. The lancet, 370(9590), 859-877.

Raes, F., Pommier, E., Neff, K. D., \& Van Gucht, D. (2011). Construction and factorial validation of a short form of the self-compassion scale. Clinical psychology \& psychotherapy, 18(3), 250-255.

Robertson, I. H., Manly, T., Andrade, J., Baddeley, B. T., \& Yiend, J. (1997). Oops!': performance correlates of everyday attentional failures in traumatic brain injured and normal subjects. Neuropsychologia, 35(6), 747-758.

Rojiani, R., Santoyo, J. F., Rahrig, H., Roth, H. D., \& Britton, W. B. (2017). Women benefit more than men in response to college-based meditation training. Frontiers in psychology, 8, 551.

Segal, Z. V., Teasdale, J. D., Williams, J. M., \& Gemar, M. C. (2002). The mindfulness-based cognitive therapy adherence scale: Inter-rater reliability, adherence to protocol and treatment distinctiveness. Clinical Psychology \& Psychotherapy, 9(2), 131-138.

Shomaker, L. B., Bruggink, S., Pivarunas, B., Skoranski, A., Foss, J., Chaffin, E., ... \& Broderick, P. (2017). Pilot randomized controlled trial of a mindfulness-based group intervention in adolescent girls at risk for type 2 diabetes with depressive symptoms. Complementary therapies in medicine, 32, 66-74.

Spielberger, C.D., Gorsuch, R.L., Lushene, R., Vagg, P.R., \& Jacobs, G.A. (1983). Manual for the State-Trait Anxiety Inventory. Consulting Psychologists Press, Palo Alto.

Spitzer, R. L., Kroenke, K., Williams, J. B., \& Löwe, B. (2006). A brief measure for assessing generalized anxiety disorder: the GAD-7. Archives of internal medicine, 166(10), 1092-1097. 
Struthers, C. W., Perry, R. P., \& Menec, V. H. (2000). An examination of the relationship among academic stress, coping, motivation, and performance in college. Research in higher education, 41(5), 581-592.

Tang, Y. Y., Ma, Y., Wang, J., Fan, Y., Feng, S., Lu, Q., ... \& Posner, M. I. (2007). Short-term meditation training improves attention and self-regulation. Proceedings of the National Academy of Sciences, 104(43), 17152-17156.

Tangney, J. P., Baumeister, R. F., \& Boone, A. L. (2004). High Self-Control Predicts Good Adjustment, Less Pathology, Better Grades, and Interpersonal Success. Journal of Personality.

Van Dam, N. T., Earleywine, M., \& Borders, A. (2010). Measuring mindfulness? An item response theory analysis of the Mindful Attention Awareness Scale. Personality and Individual Differences, 49(7), 805-810.

van den Hurk, P. A., Giommi, F., Gielen, S. C., Speckens, A. E., \& Barendregt, H. P. (2010). Greater efficiency in attentional processing related to mindfulness meditation. Quarterly Journal of Experimental Psychology, 63(6), 1168-1180.

Zivin, K., Eisenberg, D., Gollust, S. E., \& Golberstein, E. (2009). Persistence of mental health problems and needs in a college student population. Journal of affective disorders, 117(3), 180185. 


\section{Figures}

Figure 1. Effect Sizes of Psychological Wellbeing Indexes for Both Groups

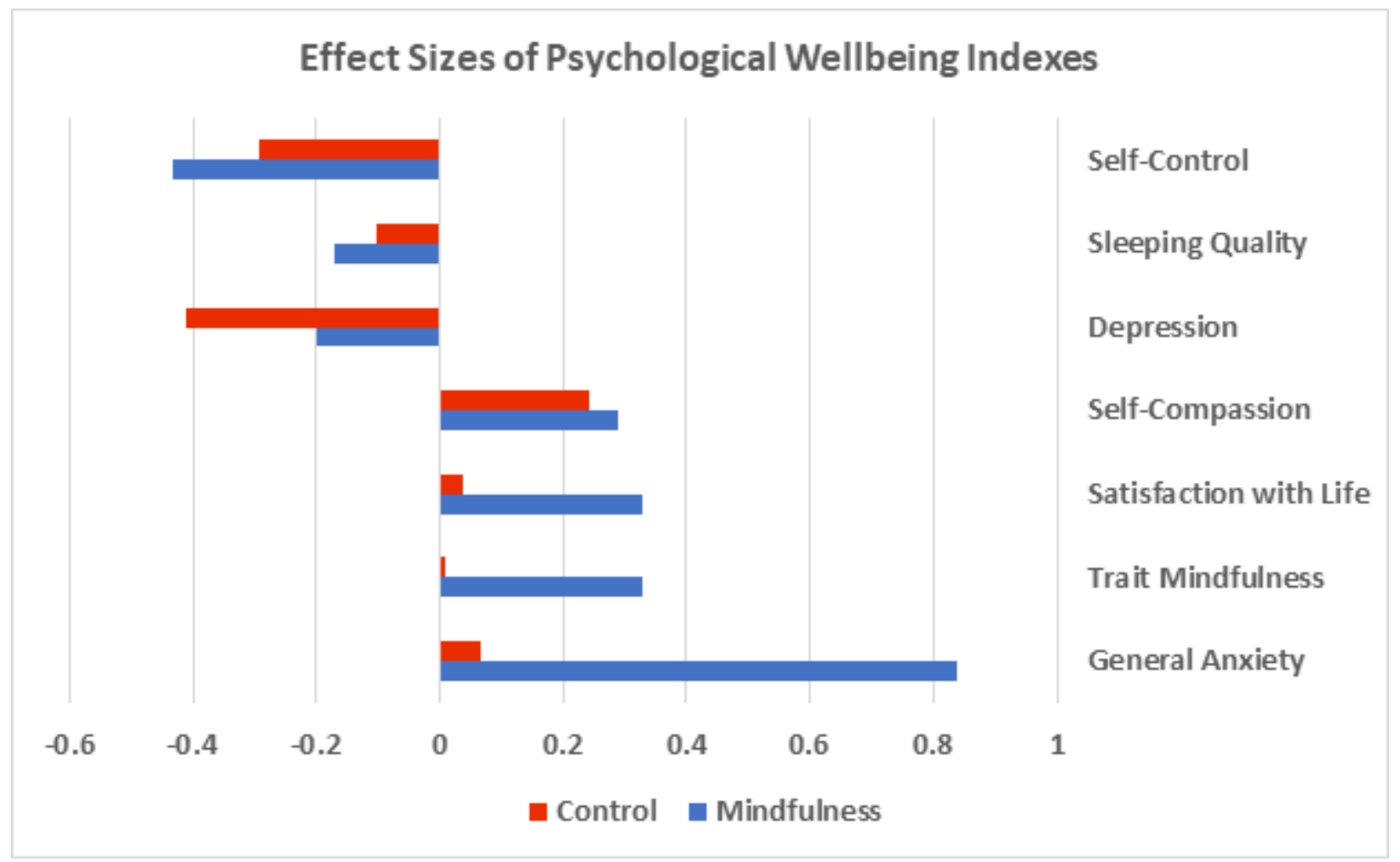


Figure 2. Effect Sizes of Cognitive Measures for Both Groups

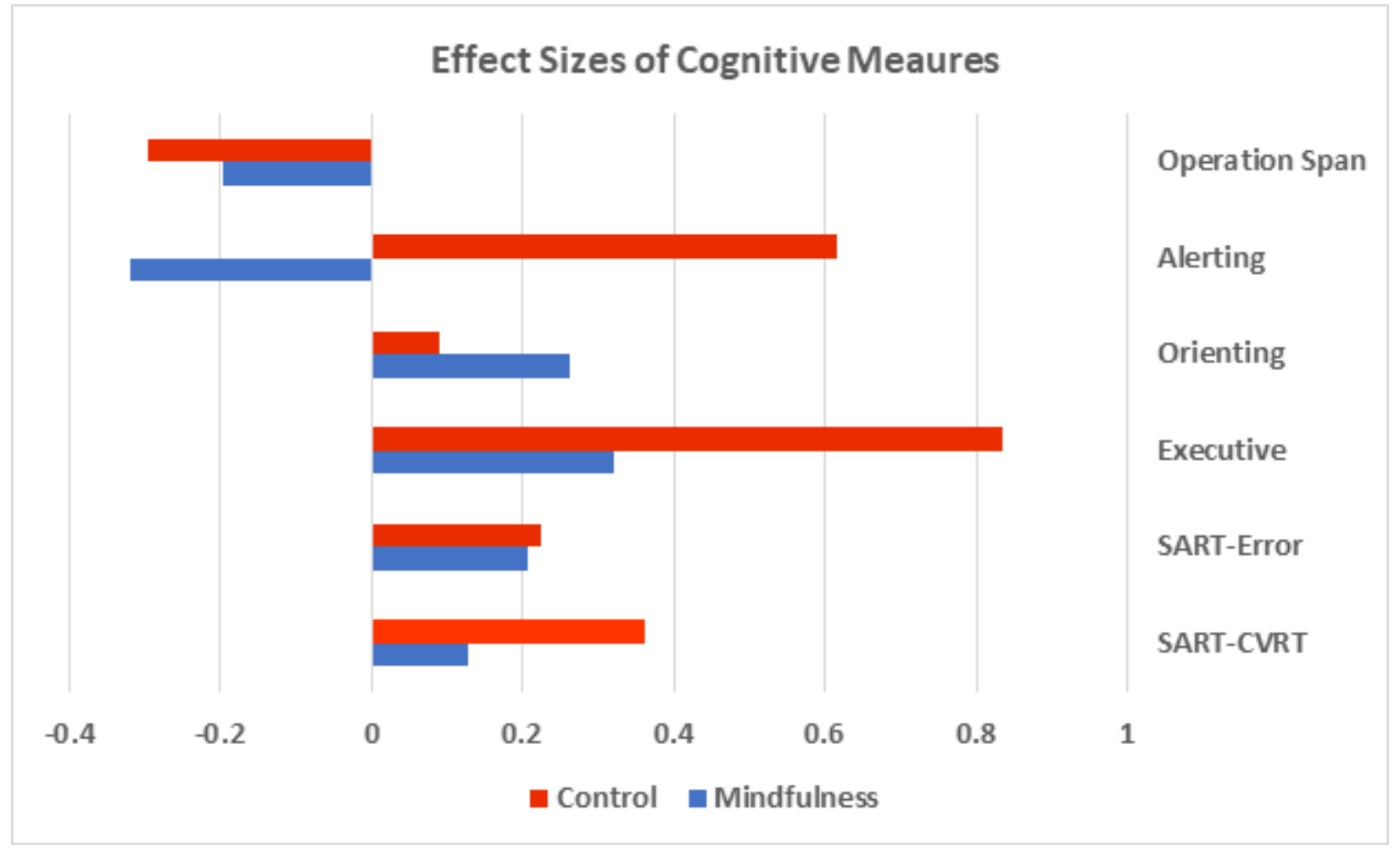


Tables

Table 1. Descriptive Statistics for Questionnaires and Cognitive Tasks

\begin{tabular}{|c|c|c|c|c|c|c|}
\hline \multicolumn{2}{|c|}{ Questionnaires } & Group & Session & $N$ & Mean & SD \\
\hline \multirow{4}{*}{\multicolumn{2}{|c|}{ Trait Mindfulness }} & \multirow[b]{2}{*}{ Mindfulness } & Pre & \multirow[t]{2}{*}{39} & 3.79 & 0.69 \\
\hline & & & Post & & 4.00 & 0.58 \\
\hline & & \multirow[b]{2}{*}{ Psychology } & Pre & \multirow[t]{2}{*}{99} & 3.83 & 0.65 \\
\hline & & & Post & & 3.83 & 0.69 \\
\hline \multirow{4}{*}{\multicolumn{2}{|c|}{$\begin{array}{l}\text { Anxiety } \\
\text { (GAD) }\end{array}$}} & \multirow[b]{2}{*}{ Mindfulness } & Pre & \multirow[t]{2}{*}{20} & 8.50 & 4.85 \\
\hline & & & Post & & 5.55 & 3.47 \\
\hline & & \multirow[b]{2}{*}{ Psychology } & Pre & \multirow[t]{2}{*}{103} & 6.71 & 4.63 \\
\hline & & & Post & & 6.46 & 4.37 \\
\hline \multirow{4}{*}{\multicolumn{2}{|c|}{$\begin{array}{c}\text { Anxiety } \\
\text { (STAI) } \\
\text { Fall 2017 \& } 2018 \\
\text { Mindfulness Class Only } \\
\end{array}$}} & \multirow{2}{*}{ State Anxiety } & Pre & \multirow{4}{*}{24} & 43.00 & 13.16 \\
\hline & & & Post & & 37.83 & 12.47 \\
\hline & & \multirow{2}{*}{ Trait Anxiety } & Pre & & 43.17 & 12.17 \\
\hline & & & Post & & 41.46 & 10.12 \\
\hline \multirow{4}{*}{\multicolumn{2}{|c|}{ Satisfaction with Life }} & \multirow[b]{2}{*}{ Mindfulness } & Pre & \multirow[t]{2}{*}{46} & 12.87 & 5.27 \\
\hline & & & Post & & 14.28 & 6.11 \\
\hline & & \multirow[b]{2}{*}{ Psychology } & Pre & \multirow[t]{2}{*}{105} & 13.84 & 5.78 \\
\hline & & & Post & & 14.09 & 5.41 \\
\hline \multirow{4}{*}{\multicolumn{2}{|c|}{ Self-Control }} & \multirow[b]{2}{*}{ Mindfulness } & Pre & \multirow[t]{2}{*}{35} & 41.00 & 8.21 \\
\hline & & & Post & & 38.80 & 8.97 \\
\hline & & \multirow[b]{2}{*}{ Psychology } & Pre & \multirow[t]{2}{*}{103} & 42.75 & 7.80 \\
\hline & & & Post & & 41.15 & 8.53 \\
\hline \multirow{4}{*}{\multicolumn{2}{|c|}{ Self-Compassion }} & & Pre & 45 & 2.87 & 0.67 \\
\hline & & Mindfulness & Post & & 3.04 & 0.69 \\
\hline & & & Pre & 100 & 2.88 & 0.64 \\
\hline & & Psychology & Post & & 2.98 & 0.58 \\
\hline & & & Pre & 39 & 6.10 & 2.63 \\
\hline & & Mindfulness & Post & & 6.51 & 3.11 \\
\hline Sleepi & uality & & Pre & 97 & 5.36 & 2.56 \\
\hline & & Psychology & Post & & 5.59 & 2.47 \\
\hline & & & Pre & 43 & 7.02 & 5.18 \\
\hline $\mathrm{De}_{1}$ & & Mindfulness & Post & & 7.93 & 4.47 \\
\hline & & & Pre & 104 & 5.30 & 3.78 \\
\hline & & Psychology & Post & & 6.81 & 4.21 \\
\hline Tasks & Variable & Group & Session & $N$ & Mean & $S D$ \\
\hline & & & Pre & 39 & 56.33 & 12.52 \\
\hline Operation & Total & Mindfulness & Post & & 53.51 & 12.74 \\
\hline Span & Span & & Pre & 11 & 53.55 & 16.36 \\
\hline & & Psychology & Post & & 48.18 & 17.95 \\
\hline & & & Pre & 39 & 52.21 & 26.72 \\
\hline & & Mindfulness & Post & & 47.28 & 27.57 \\
\hline
\end{tabular}




\begin{tabular}{|c|c|c|c|c|c|c|}
\hline \multirow{2}{*}{$\begin{array}{c}\text { Sustained } \\
\text { Attention to } \\
\text { Response }\end{array}$} & \multirow{2}{*}{$\begin{array}{c}\% \\
\text { Commission } \\
\text { Error } \\
\end{array}$} & \multirow[b]{2}{*}{ Psychology } & Pre & \multirow[t]{2}{*}{15} & 31.73 & 22.70 \\
\hline & & & Post & & 28.00 & 25.21 \\
\hline \multirow{4}{*}{$\begin{array}{l}\text { Sustained } \\
\text { Attention to } \\
\text { Response }\end{array}$} & \multirow{4}{*}{$\begin{array}{c}\text { Coefficient of } \\
\text { Variability }\end{array}$} & \multirow[b]{2}{*}{ Mindfulness } & Pre & \multirow[t]{2}{*}{39} & 0.274 & 0.097 \\
\hline & & & Post & & 0.261 & 0.113 \\
\hline & & \multirow[b]{2}{*}{ Psychology } & Pre & \multirow[t]{2}{*}{15} & 0.208 & 0.065 \\
\hline & & & Post & & 0.183 & 0.066 \\
\hline \multirow{4}{*}{$\begin{array}{c}\text { Attention } \\
\text { Network Test }\end{array}$} & \multirow{4}{*}{ Alerting } & \multirow[b]{2}{*}{ Mindfulness } & Pre & \multirow[t]{2}{*}{37} & 63.79 & 34.62 \\
\hline & & & Post & & 73.42 & 37.12 \\
\hline & & \multirow[b]{2}{*}{ Psychology } & Pre & \multirow[t]{2}{*}{14} & 56.80 & 25.53 \\
\hline & & & Post & & 40.97 & 30.17 \\
\hline \multirow{8}{*}{$\begin{array}{c}\text { Attention } \\
\text { Network Test }\end{array}$} & \multirow{4}{*}{ Orienting } & \multirow[b]{2}{*}{ Mindfulness } & Pre & \multirow[t]{2}{*}{37} & 25.39 & 20.07 \\
\hline & & & Post & & 15.99 & 33.99 \\
\hline & & \multirow[b]{2}{*}{ Psychology } & Pre & \multirow[t]{2}{*}{14} & 22.05 & 11.93 \\
\hline & & & Post & & 20.00 & 16.70 \\
\hline & \multirow{4}{*}{ Executive } & \multirow[b]{2}{*}{ Mindfulness } & Pre & \multirow[t]{2}{*}{37} & 74.01 & 27.83 \\
\hline & & & Post & & 61.37 & 35.87 \\
\hline & & \multirow[b]{2}{*}{ Psychology } & Pre & \multirow[t]{2}{*}{14} & 78.49 & 19.09 \\
\hline & & & Post & & 61.05 & 23.93 \\
\hline
\end{tabular}

